\title{
Enquadramento noticioso e construção narrativa do impeachment de Dilma Rousseff nos jornais Folha de S. Paulo, Estado de S. Paulo e O Globo
}

\author{
News framing and narrative construction of Dilma Rousseff's \\ impeachment in the newspapers Folha de S. Paulo, Estado de S. \\ Paulo and $O$ Globo
}

\section{Rafael Cardoso Sampaio / Carla Rizzotto / Daniela Rocha Drummond / Crislaine Franco Rocha / Bruno Nichols Washington / Djiovanni Jonas França Marioto}

\begin{abstract}
Resumo
Este artigo busca analisar como se deu a construçấo narrativa da destituiçâo da presidenta Dilma Rousseff nos principais jornais brasileiros, avaliando tanto categorias da narrativa quanto do enquadramento noticioso. O corpus é formado por 2.272 notícias publicadas pelos três principais jornais brasileiros desde o início da tramitação do processo - dezembro de 2015 - até a saída definitiva de Dilma Rousseff - agosto de 2016. Por meio da análise de conteúdo, verificou-se que o julgamento predominante da narrativa jornalística culpou Dilma e aliados. Houve destaque, enquanto recomendaçáo de tratamento, à ideia de que o impeachment era a melhor soluçáo. Em relaçáo à identificaçáo dos personagens, percebeu-se que os atores políticos ligados a Dilma obtiveram maior destaque como vítimas e vilóes (e năo heróis). Enfim, concluímos que o jornalismo não conseguiu escapar das narrativas políticas cotidianas, sem conseguir demonstrar a real magnitude e complexidade desse acontecimento político.
\end{abstract}

\section{Palavras-chave}

Enquadramento; Impeachment; Análise de Narrativa; Comunicação e Política.

\begin{abstract}
This article analyzes how the narrative of Brazilian President Dilma Rousseffs impeachment was constructed in the main Brazilian newspapers, evaluating both categories of the narrative and the news framing. The corpus consists of 2,272 news stories published by the three major Brazilian newspapers from the beginning of the procedure - December 2015 - to the definitive removal of Dilma Rousseff - August 2016. Using content analysis, we found that the prevailing judgment of the journalistic narrative blamed Ms. Rousseff and allies. There was a prominence of the idea that impeachment was the best solution. In relation to the identification of narrative roles, we noticed that the political actors related to Rousseff obtained greater prominence as victims or villains (not heroes). Finally, we conclude that journalism has not been able to escape everyday political narratives and could not demonstrate the real magnitude and complexity of this political event.
\end{abstract}

\section{Keywords}

Framing; Impeachment; Narrative Analysis; Political Communication. 


\section{Introdução}

$\mathrm{O}$ pedido de impeachment da presidenta Dilma a acusava de ter cometido as chamadas "pedaladas fiscais", operações contábeis do Tesouro Nacional que visam atrasar de forma proposital o repasse de dinheiro para bancos (públicos e também privados) e autarquias, o que foi interpretado como crime de responsabilidade. $\mathrm{O}$ então presidente da Câmara dos Deputados, Eduardo Cunha, acatou o processo, que teve início em 2 de dezembro de 2015. Em 17 de abril de 2016, os deputados aprovaram o pedido do impeachment com uma votação de 367 votos a favor e 137 votos contra, numa sessão que foi transmitida em tempo real por quase todos os canais de televisão, rádio e também pela Internet.

Após a sua aprovação pela Câmara, o processo seguiu para o Senado Federal, onde a admissibilidade do pedido foi votada no dia 12 de maio de 2016, com 55 votos a favor e 22 contra. O senador Antonio Anastasia, do PSDB, partido da oposição ao governo Dilma, foi o relator do processo. Dilma foi afastada por 180 dias e o vice-presidente Michel Temer assumiu interinamente a presidência da República. $\mathrm{Na}$ votação final do impeachment, que ocorreu no dia 31 de agosto, Dilma foi definitivamente afastada, com 59 votos a favor e 21 contra. Apesar da cassação, ela manteve a elegibilidade.

A jovem democracia brasileira apresenta muitas semelhanças com seus vizinhos latino-americanos, países como Argentina e Chile, que também viveram períodos de golpes militares e ditadura e engatinham para consolidar a democracia. O Brasil havia passado por um processo de impeachment do presidente Fernando Collor, em 1992. Além do Brasil, de 1994 a 2004, outros seis presidentes da América Latina passaram por esse processo, e quatro foram afastados do governo (PÉREZ-LIŃAN, 2007).

Esses atos mostram a instabilidade das democracias desses países. Nesse sentido, Pérez-Liñan (2007) questiona se os impeachments não seriam uma nova forma de golpe para "substituir" os antigos golpes militares. Estaríamos testemunhando uma mudança nas relações entre Executivo e Legislativo na região? Já que os golpes militares não são mais aceitos em contextos democráticos, buscam-se formas constitucionais para se resolver as disputas políticas; é nesse momento, segundo Pérez-Liñan (2007), que o impeachment se torna um recurso para o afastamento de presidentes indesejáveis, como foi o caso de Dilma Rousseff no Brasil. Para o teórico, há três atores relevantes para o processo de impeachment: a mídia, o Legislativo e o público. 
Este estudo concentra-se na mídia, que, no entendimento do autor, tem o poder de conceder visibilidade à opiniáo pública, o que serve de embasamento para os atores do judiciário. A importância da mídia dentre os três atores citados deve-se ao seu papel de reguladora entre a política e os cidadãos. A mídia escolhe o que é noticiável, seleciona o quê ou quais políticos devem ter visibilidade e expóe o comportamento de outros políticos quando estes gostariam de mantê-lo escondido dos olhos do público (PÉREZ-LIÑAN, 2007).

No caso do impeachment de Dilma Rousseff, a cobertura jornalística desses acontecimentos foi alvo de diversas críticas, que afirmavam que os vieses tinham como objetivo direcionar a interpretação dos leitores, tanto contra como, especialmente, a favor do impedimento da presidenta (ALVES et al., 2018; AZEVEDO, 2017), especialmente quando as pesquisas acadêmicas já apontaram que os principais noticiários brasileiros tendem a ter um viés notadamente negativo contra o Partido dos Trabalhadores (PT) e seus integrantes (BIROLI e MANTOVANI, 2014; FERES JÚNIOR e SASSARA, 2016). Os enquadramentos são importantes estratégias que direcionam tal influência, uma vez que "[...] oferece um caminho para descrever o poder do texto comunicacional e sua influência sobre a consciência humana, exercida pela transferência da informação [...] através de uma declaração, expressão ou reportagem" (ENTMAN, 1993, p. 51-52, tradução nossa).

A pesquisa teve como objetivo realizar uma análise de enquadramento multimodal (WOZNIAK, LÜCK e WESSLER, 2014), que envolve o enquadramento noticioso, bem como a construção narrativa e imagética, da cobertura do impeachment por três dos mais importantes jornais brasileiros, a Folha de $S$. Paulo, O Globo e O Estado de S. Paulo, durante todo o processo - desde o início do trâmite, em 2 de dezembro de 2015, até o afastamento definitivo da presidenta, em 31 de agosto de 2016. A análise de enquadramento multimodal é vantajosa pois permite, de um lado, verificar detalhes que passam despercebidos pela análise de enquadramento clássica e, de outro, apontar incongruências da cobertura jornalística (RIZZOTTO, PRUDENCIO e SAMPAIO, 2017).

Neste artigo, todavia, focamos em dois dos três aspectos - a construção narrativa da cobertura e a análise de enquadramento, compreendendo que cada forma de análise, separadamente, pode render dados e interpretações pertinentes. No entanto, é o cruzamento entre as duas que pode mostrar as minúcias do enviesamento favorável ao impeachment de Dilma Rousseff. Em suma, as empresas jornalísticas optaram por posicionamentos explícitos e, em sua maioria, favoráveis ao impeachment em seus editoriais (GUAZINA, PRIOR e ARAÚJO, 2017; 
MARQUES, MONT'ALVERNE e MITOZO, 2017); entretanto, há, supostamente, um posicionamento mais neutro ou "isento" nas notícias, conforme demonstramos em trabalhos anteriores (RIZZOTTO, PRUDENCIO e SAMPAIO, 2017; PRUDENCIO, RIZZOTTO e SAMPAIO, 2018).

Nossa hipótese é que os veículos conduziram a narrativa do impeachment como uma solução positiva, sem se aprofundar em debates sobre as consequências desse processo, "naturalizando" como algo simples e corriqueiro nos regimes democráticos. Evidencia-se que o jornalismo brasileiro, intencionalmente ou não, apoiou o impeachment de duas formas diferentes: a primeira ao se focar exclusivamente no conflito político, não sendo capaz de fazer reflexões mais amplas sobre a particularidade do processo em si (como já denotamos em trabalhos anteriores), e a segunda, foco principal do trabalho, por meio de uma narrativa que, quando se manifestou em relação ao impeachment, foi favorável a este e favoreceu os opositores da presidenta.

\section{Narrativa jornalistica e enquadramento}

Partimos da premissa que explica que as narrativas são dispositivos argumentativos usados nos jogos de linguagem. Como afirma Motta (2005, p. 2), a forma como contamos os acontecimentos na narrativa está impregnada pela narratividade, que é a "[...] qualidade de descrever algo enunciando uma sucessão de estados de transformação", ou seja, a narrativa traduz o conhecimento objetivo e subjetivo do mundo em relatos.

É importante salientar que as narrativas são recursos discursivos que os jornalistas utilizam socialmente de acordo com suas pretensôes, além de serem formas de relações estabelecidas por causa da cultura, das condiçôes sociais e hierarquias de poder. Partimos do pressuposto de que nenhuma narrativa é ingênua; assim, a análise busca compreender as estratégias do narrador. Toda narrativa gira em torno do conflito, e é essa expectativa em torno do desenlace das histórias que mantém as notícias nos jornais. A narrativa jornalística contém na maioria das vezes conotaçóes dramáticas imediatas e negativas, que irrompem, desorganizam e transtornam (MOTTA, 2005).

$\mathrm{Na}$ narrativa jornalística, interessa como se constrói a imagem de um personagem e quais as açôes dele no texto. $\mathrm{O}$ narrador define as marcas que pretende transmitir para seus leitores; entretanto, o personagem do jornalismo está diretamente ligado à pessoa da vida real, o que gera uma complexidade singular, uma vez que não 
se trata de personagem puramente ficcional. Uma das estratégias do narrador jornalístico é o de dar ares de realidade ao seu relato, quando, na observação do mundo atual, o jornalista ancora seu relato no presente e busca antecipar o futuro, fazendo uma mediação simultaneamente linguística e temporal (CORREIA, 2011; MESQUITA, 2002; MOTTA, 2005).

Motta (2005) afirma que o texto jornalístico também tem como característica ser fortemente determinado por um fundo ético ou moral. Os fatos selecionados da realidade são aqueles que transgridem algum preceito ético ou moral, alguma lei, algum consenso cultural. Segundo o autor, a linguagem jornalística é dramática, e a sua retórica é tão ampla e rica quanto a literária. "Em qualquer produção noticiosa, também temos uma mobilização de recursos narrativos tradicionais que é mais visível e explorada em torno de emoçóes e melodramas no jornalismo que privilegia a dimensão sensacional de ocorrências e declaraçôes" (CORREIA, 2011, p. 60). Enfim, a análise da narrativa jornalística deve observar particularmente o "contrato cognitivo" implícito entre jornalistas (narradores) e audiência (narratário) em seu contexto operacional. Esse "contrato" segue as máximas da objetividade e da coconstrução da "verdade dos fatos": o objetivo é co-construir a verdade, a "realidade objetiva” (MOTTA, 2005).

$\mathrm{Na}$ perspectiva que adotamos, percebemos o conflito como uma categoria analítica e como um valor-notícia. Como afirmam Motta e Guazina (2010, p. 133) "[...] o conflito é uma categoria dramática que centraliza a narrativa jornalística e tece os fios que encadeiam as ações das personagens da política”, além disso, o conflito divide o noticiário sob uma perspectiva maniqueísta, na qual os personagens da notícia são colocados uns contra os outros. $\mathrm{O}$ conflito, assim, é a categoria principal da notícia, formada também pelas subcategorias protagonista, antagonista e adversário. Em nossa análise, identificamos como subcategorias os papeis de vítimas, heróis e vilóes, que acreditamos ser de presença constante nas notícias, uma vez que serve ao propósito de simplificar e reificar controvérsias.

Motta e Guazina (2010) dão ao conflito um estatuto mais denso, considerando-o uma das essências da política, e a política a expressão do conflito entre os grupos, partes e partidos. O conflito está nas diferenças de acessos a recursos e às oportunidades. Assim, quem é situação tenta manter-se no poder, ou mesmo quem não detém um cargo político, mas está em situação vantajosa, tenta assegurar a permanência do grupo que governa, enquanto os que são oposição ou se sentem lesionados tentam mudar o contexto. O conflito está justamente nessas tensões e disputas. 
O jornalismo se apropria dessa visão dualista, adaptando o conflito como categoria estruturadora da sua retórica dramatizada. O relato dos conflitos aquece as notícias e as deixa mais atraentes, mas a cobertura do conflito a amplifica e demarca disputas; dessa forma, a mídia se torna um agente acirrador dos conflitos (MOTTA e GUAZINA, 2010).

Passando para o segundo aspecto considerado neste artigo, o enquadramento, cabe destacar a esse respeito o grande número de pesquisas que mobilizam tal conceito ao se debruçar sobre os imbricamentos entre mídia, sociedade e política. De acordo com Mendonça e Simóes (2012, p. 191), “[...] tal interesse se deve à percepção de que quadros específicos adquirem visibilidade nos media e atravessam outros processos sociais". Compreendemos que os estudos sobre enquadramento na perspectiva da comunicação política (MENDONÇA e SIMÓES, 2012) estão basicamente fazendo uso de um quadro conceitual/operacional que busca justamente compreender como se deu a narrativa jornalística sobre determinado tema, evento, fenômeno etc. Em outras palavras, o enquadramento pode ser entendido como um instrumento de análise de conteúdo das notícias, cujo objetivo é identificar, na formatação das notícias, elementos que privilegiem determinada interpretação dos fatos (CORREIA, 2011; VIMIEIRO e MAIA, 2011).

Do ponto de vista operacional, o enquadramento envolve a seleção do que é narrado na busca de deixar a informação mais noticiável e significativa para a audiência. Enfim, "[...] o enquadramento determina se a maioria das pessoas percebe e como elas compreendem e se lembram de um problema, da mesma forma que determina a maneira que avaliam e escolhem a forma de agir sobre ele" (ENTMAN, 1993, p. 52).

\section{Metodologia e resultados}

Tendo como objetivo verificar a cobertura completa do impeachment, desde a abertura do processo (02/12/2015) até o afastamento definitivo da presidenta Dilma Rousseff (31/08/2016), foi realizada uma coleta automática de todas as notícias de cadernos de política que contivessem a palavra-chave impeachment nos três jornais impressos de maior circulação nacional, o que gerou um corpus de 2.272 matérias (727 Estadão, 877 O Globo, 668 Folha de S. Paulo).

$\mathrm{Na}$ análise de enquadramento (Cf. ENTMAN, 1993), o estudo verificou a definição do problema, percebendo quais atores tinham maior espaço de fala nas notícias. Ausentes quando a notícia era essencialmente descritiva e não havia o uso de 
fontes; ou então pertencentes ao campo político (como aliados de Dilma e Lula ou como aliados de Michel Temer e Eduardo Cunha), ao campo econômico, ao campo judiciário, membros da sociedade civil ou outro. Os resultados mostraram que, antes do afastamento provisório da presidenta, os atores mais presentes nas notícias eram aqueles do campo político, com frequência semelhante entre seus aliados $(29,3 \%)$ e seus opositores $(30,6 \%)$. Depois do afastamento, atores do campo político continuam sendo as fontes mais frequentes, entretanto, a diferença entre aliados $(18,8 \%)$ e opositores $(35,3 \%)$ é mais significativa (PRUDENCIO, RIZZOTTO e SAMPAIO, 2018).

Em seguida foi verificado em qual subtópico a notícia melhor se adequava, levando em consideração o texto, a manchete, o lide e a imagem. Os possíveis subtópicos aos quais chegamos após a leitura flutuante do material são os que seguem: disputa política; processo de impeachment; repercussão na população; recuperação histórica; futuro pós-impeachment; e cenário de crise. Cenário de crise mostrou-se o tema mais frequente, presente em $31,8 \%$ das notícias analisadas (PRUDENCIO, RIZZOTTO e SAMPAIO, 2018).

Também se verificou quais foram as causas ou razóes do problema apontado: ausente; contenda política/ideológica; incapacidade política do governo Dilma; legalidade/legitimidade do processo de impeachment; corrupção; interferência do judiciário. Nesse ponto identificamos a maior frequência de notícias que apontavam a contenda político-ideológica como a principal causa atribuída, num total de 30,8\% das notícias (PRUDENCIO, RIZZOTTO e SAMPAIO, 2018), corroborando o que dizem Motta e Guazina (2010) sobre o papel da mídia enquanto agente acirrador dos conflitos.

O estudo seguiu analisando a presença de um julgamento moral do assunto, ainda que tal juízo estivesse presente somente na voz de fontes e citações. Grande parte das notícias, e isso já era esperado devido às características do modo de fazer jornalismo no Brasil, não apresentou qualquer julgamento (71,9\%). Atribuiu-se culpa à Dilma e aliados em 10,7\% do corpus; julgou-se as brigas políticas em 7,8\%; a forma do impeachment em 5,2\%; e, por último, apresentou-se juízo sobre a vingança por trás do impeachment em $4,1 \%$. Finalmente, foi verificado se a notícia propóe alguma solução para o problema que expõe, classificando como: ausente $(80,6 \%)$; o impeachment é/foi a melhor solução (11,5\%); o impeachment não é/foi a melhor solução (6,6\%); realização de novas eleições (1\%) (PRUDENCIO, RIZZOTTO e SAMPAIO, 2018). 
Tendo em vista as características da narrativa jornalística já descrita, nosso estudo leva em consideração o grau de narratividade, o gênero narrativo e os atores identificados em seus respectivos papéis, conforme proposto por Wozniak, Lück e Wessler (2014). A narratividade é avaliada em uma série de variáveis, nomeadamente - i) dramatização, quando a notícia apresentou uma história com ordem sequencial, com início, meio e fim; ii) emoção, quando a matéria descreveu o estágio emocional de um ou mais sujeitos; iii) personalização, momento no qual a história contada foca nos sujeitos e em suas açôes; e iv) ornamentação estilística, determinada pelo uso do estilo literário pelo jornalista, ultrapassando a descriçáo dos acontecimentos. Verificamos que uma parte considerável do corpus era focada em um sujeito específico (personalização, com 47\%). A emoção também foi estratégia narrativa bastante frequente $(31,4 \%)$. Dramatização e ornamentação estilística foram utilizadas com menor frequência, com 20,6\% e 13,9\%, respectivamente (PRUDENCIO, RIZZOTTO e SAMPAIO, 2018).

A análise da narrativa também compreende a verificação dos papéis - herói ${ }^{1}$, vilão $^{2}$ e vítima ${ }^{3}$ - associados aos sujeitos representados nas notícias ${ }^{4}$. Apenas $13 \%$ das notícias representaram uma vítima, mas, quando assim o fizeram, Dilma Rousseff foi a vítima mais recorrente; $15,6 \%$ apresentaram a figura do vilâo (ora Dilma, ora Cunha, ora Temer); e 8,6\% exaltaram algum personagem enquanto herói - Temer é o herói mais frequente nas publicações após o afastamento provisório de Dilma; Dilma e Lula aparecem mais vezes como heróis antes do afastamento (PRUDENCIO, RIZZOTTO e SAMPAIO, 2018).

\section{Narrativa e enquadramento se encontram}

Em artigos anteriores, já exploramos os principais resultados das frequências simples das categorias, que indicaram, grosso modo, uma cobertura despolitizada do impeachment $t^{5}$. As variáveis de narrativa, em sua maioria, apresentaram resultados

\footnotetext{
${ }^{1}$ Qualquer pessoa, grupo ou instituição que seja admirado por seu sucesso, sua coragem, resultados ou qualidades nobres. O herói também aparece quando age para defender uma vítima ou lutar contra o vilão.

${ }^{2}$ Qualquer pessoa, grupo, instituição ou “coisa” responsável por problemas específicos, prejuízos ou danos em relação a outros.

${ }^{3}$ Uma pessoa, grupo ou instituição é prejudicado (= ferido, morto) ou sofre a ação.

4 O livro de códigos pode ser acessado integralmente em <https://bdc.c3sl.ufpr.br/handle/ 123456789/27>. Acesso em: 18 maio 2018.

5 Os resultados completos das categorias estão disponíveis em Prudêncio, Rizzotto e Sampaio (2018).
} 
baixos, evidenciando o modelo jornalístico brasileiro que se apoia em textos mais informativos e neutros. Da mesma forma, os valores da categoria do enquadramento também não foram notáveis, uma vez que a maioria das matérias não fez julgamentos morais nem apresentou soluçôes para o problema.

Com o objetivo de verificar nossa hipótese de viés contrário a Dilma e aliados, cruzamentos foram realizados no sentido de verificar como a temática do impeachment da entáo presidenta Dilma Rousseff apareceu nas matérias dos jornais Folha de S. Paulo, Estado de São Paulo e O Globo. Para tanto, verificamos apenas os casos em que havia a presença das diferentes variáveis analisadas para a realização dos cruzamentos (logo, foram ignorados os casos ausentes). Assim, o primeiro gráfico diz respeito ao cruzamento entre as diferentes variáveis da narrativa com aquelas do julgamento moral.

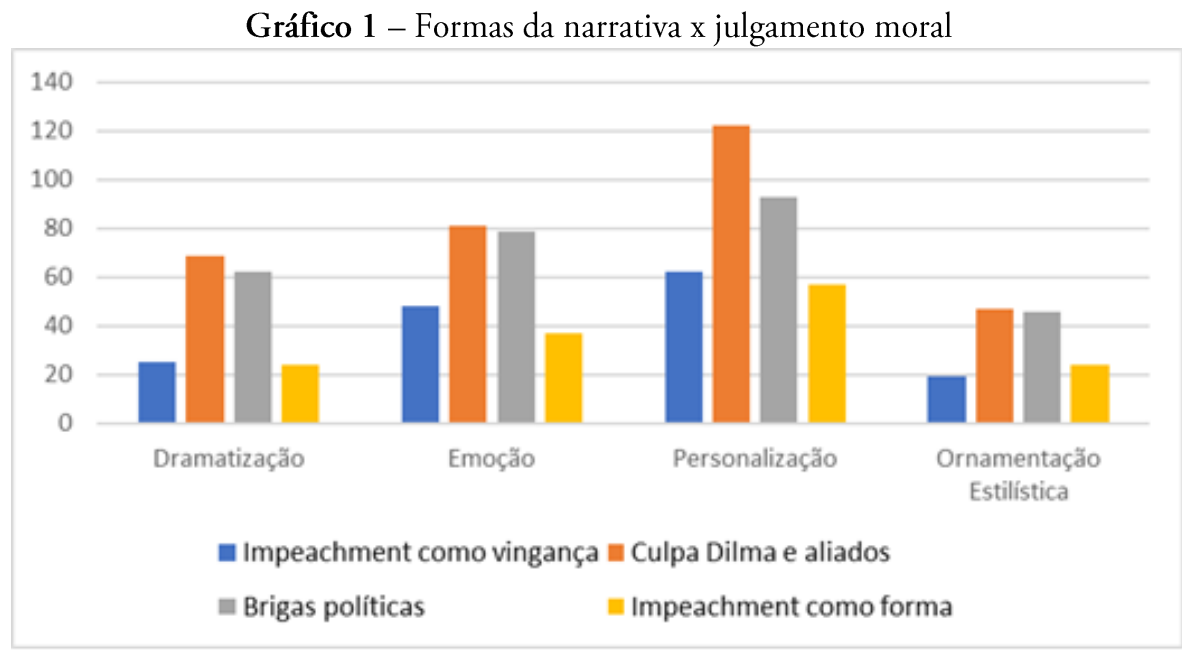

Fonte: Elaboração própria ${ }^{6}$.

O gráfico acima dispóe o tipo de julgamento utilizado em cada categoria de narrativa. Deste modo, percebe-se que a narrativa dramática foi dominada por dois tipos de julgamento: "culpa Dilma e aliados" (10,7\%) e "brigas políticas" (7,8\%), respectivamente. As categorias de julgamento menos utilizadas nesse tipo de narrativa

\footnotetext{
${ }^{6} \mathrm{O}$ cruzamento feito possui uma associação estatística significativa, com qui-quadrado maior que 25,216 e sig , $000^{*}$ em todos os casos deste gráfico. Já as análises de correlação revelaram uma relação negativa entre as formas narrativas e o julgamento moral, $r s=-0,128$, rs $=-0,103$, $r s=-0,79$ e $r s=-0,147$ (todos os $\mathrm{p}<0,01$ ).
} 
são "impeachment como vingança" e "impeachment como forma". De modo geral, essa tendência no uso dos julgamentos se repete nos demais tipos de narrativa, observando sempre a mesma ordem do que foi apresentado na categoria dramatização, variando somente na intensidade. Destaca-se o equilíbrio no uso dos julgamentos em todos os tipos narrativos, excetuando a categoria "narrativa personalizada”, na qual há maior utilização de elementos culpando Dilma Rousseff e seus aliados ao longo do processo de impeachment.

Posteriormente, cruzamos as mesmas variáveis de narratividade refletidas no Gráfico 1 com a variável "recomendação de tratamento", buscando entender como a narrativa se comportou de acordo com as diferentes soluçóes apresentadas para o problema do impeachment.

Gráfico 2 - Narrativa x recomendação de tratamento

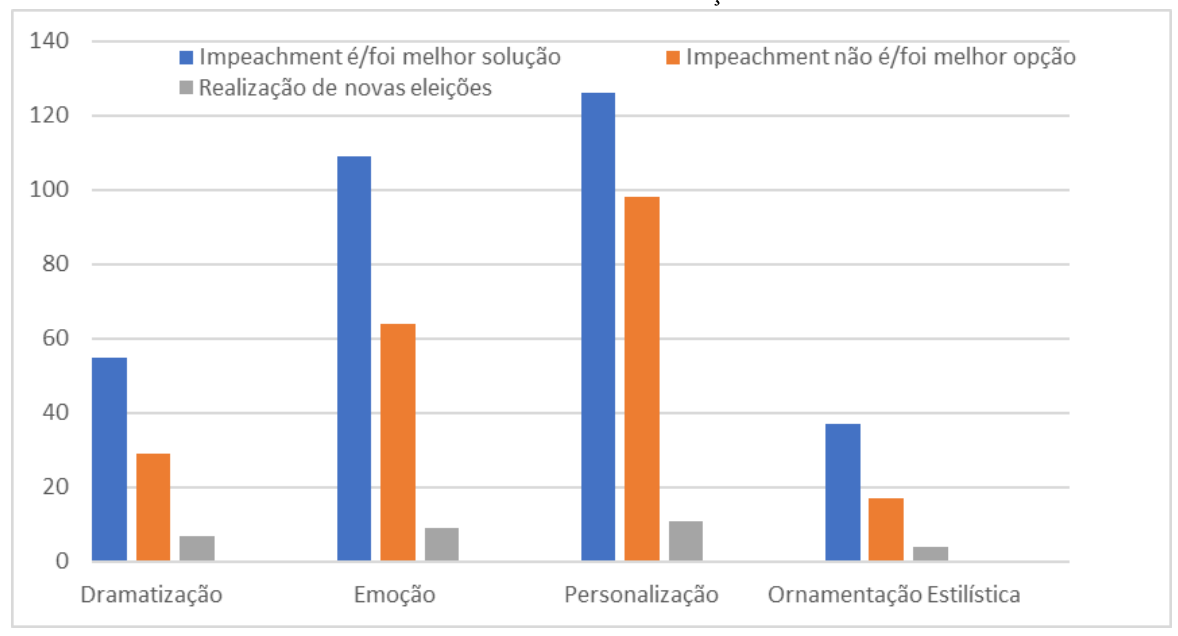

Fonte: Elaboração própria ${ }^{7}$.

O cruzamento entre narrativa e recomendação de tratamento das matérias expõe, primeiramente, a dominância da ideia de que impeachment é ou foi a melhor solução em todos os tipos de narrativa. Repetindo um padrão visto no gráfico anterior, aqui também há semelhança na disposição do tipo de recomendação de

\footnotetext{
7 É possível afirmar que o cruzamento feito possui uma associação significativa entre as variáveis emoção, personalização e ornamentação estilística. Porem somente a variável personalização estava correlacionada significativamente com a recomendação de tratamento, rs=0,123, $\mathrm{p}<0,05$.
} 
tratamento para cada narrativa, estando na seguinte ordem hierárquica quanto a seu uso: impeachment é/foi melhor solução > impeachment não é/foi melhor solução > realização de novas eleições.

Realizados os cruzamentos relacionados à narratividade, parte-se agora para o estudo da identificação dos personagens - identificados como vítimas, vilóes ou heróis - em função dos atores que tiveram maior espaço de fala em uma matéria, conforme representado a seguir:

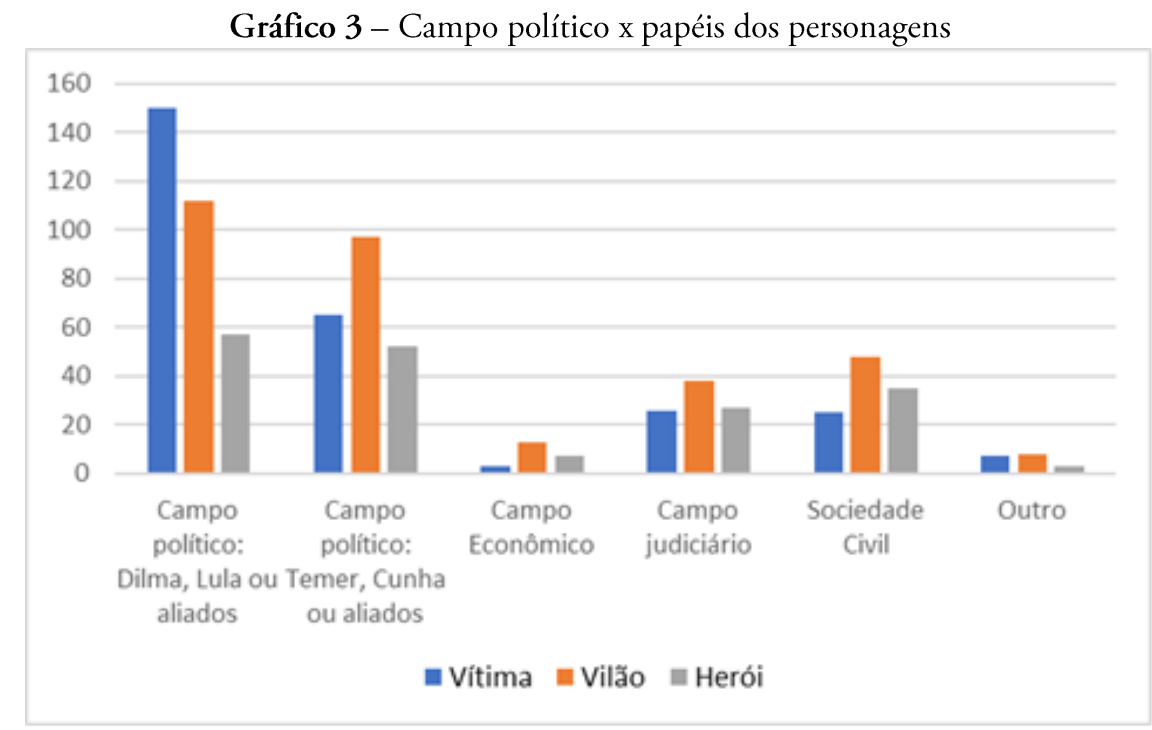

Fonte: Elaboração própria ${ }^{8,9}$.

De acordo com os dados acima expostos, percebe-se que os atores políticos ligados a Dilma e Lula obtiveram maior destaque como vítimas quando lhes era dado espaço de fala nas matérias dos jornais analisados. Ao contrário do que foi visto nos gráficos anteriores, não há repetição de padrão entre as categorias. $\mathrm{Na}$ categoria "campo político: Temer, Cunha ou aliados", nota-se a primeira diferença: em vez de aparecerem majoritariamente como vítimas, foram tratados como vilóes. Já para o

${ }^{8}$ É possível afirmar que o cruzamento feito possui uma associação significativa do ponto de vista estatístico, possuindo qui-quadrado maior que 21,738 e sig ,000* em todos os casos deste gráfico. Apenas o papel de vítima está correlacionado positivamente com o campo político, rs=0,177, $\mathrm{p}<0,01$. 9 Analisando o resíduo padrão é possível perceber que existe uma concentração maior do que o esperado na marcação de vítima quando se tratava da "Dilma, Lula e aliados" $(7,4)$. 
campo judiciário e sociedade civil, a dinâmica foi similar, com dominância de "vilão", "herói" e "vítima", nessa ordem.

Após comparar a identificação dos personagens em relação à predominância que os principais grupos sociais tiveram nas matérias relacionadas ao processo, os dados abaixo são a respeito do entendimento de como foi o julgamento moral quanto às variáveis de vítima e vilão, buscando entender se há, de fato, julgamento moral e como Dilma Rousseff, peça central nesse processo, foi majoritariamente vista.

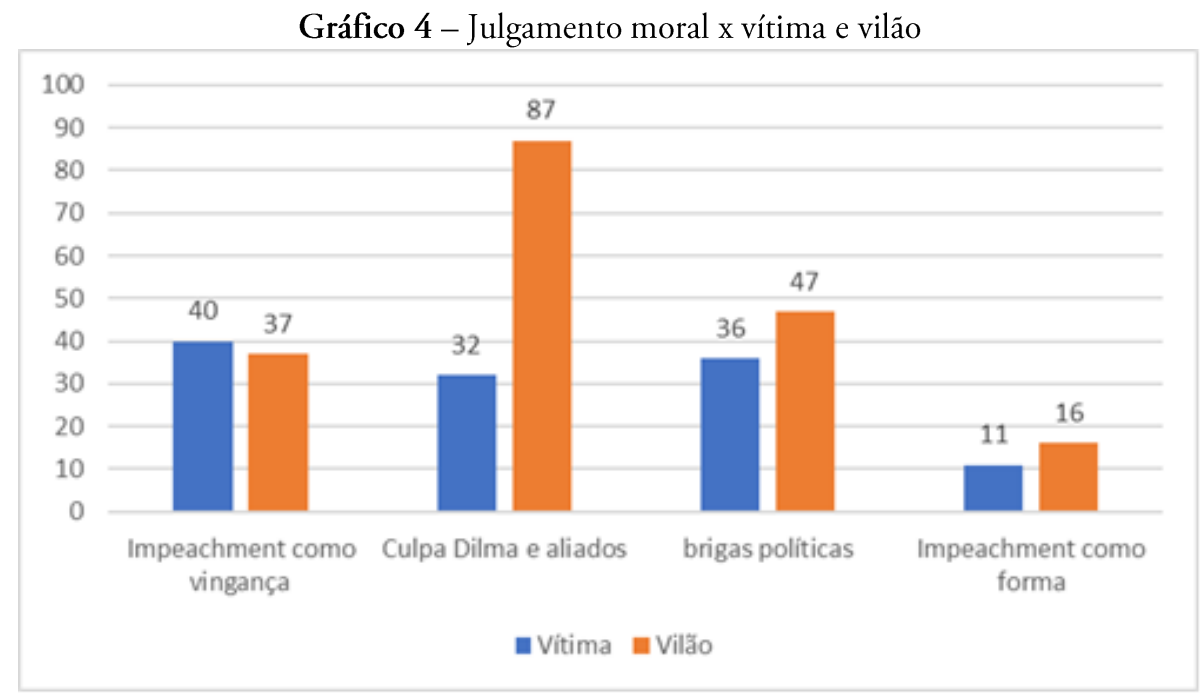

Fonte: Elaboração própria ${ }^{10,11}$.

De acordo com os dados acima, algumas consideraçóes precisam ser ponderadas: em primeiro lugar, o julgamento moral percebido nas matérias que tratavam o impeachment como uma forma de vingança apresenta equilíbrio quanto ao tom verificado, ou seja, há nessa narrativa tanto heróis quanto vilóes. Sabe-se, do contexto do processo, que a ideia de vingança é atribuída a Eduardo Cunha, que teria

\footnotetext{
${ }^{10}$ É possível afirmar que o cruzamento feito é uma associação significativa no ponto de vista estatístico, com qui-quadrado maior que 95,327 e sig , $000^{*}$ em todos os casos deste gráfico. As variáveis vítima e viláo se correlacionam positivamente com o julgamento moral, rs=0,170 e rs=0,192 (todos $\mathrm{p}<0,01$ ).

11 Analisando o resíduo padrão é possível perceber que existe uma concentração maior do que o esperado na marcação da presença de vítima quando se tratava do "impeachment como vingança" $(5,3)$.
} 
acatado o processo uma vez que três deputados do PT votaram pela continuidade do processo de cassação contra ele. Se o juízo embutido na notícia diz respeito a uma apreciação negativa da ideia de vingança, infere-se daí que Cunha é o vilão dessa narrativa, mas quem seriam os heróis? A matéria do Estadão, de 18 de abril de 2016, intitulada "Lula já articula resistência a Temer", mostra Lula como herói, que "[...] vai se dedicar a articular a resistência contra um eventual governo Michel Temer", e, representaria - para os petistas - "o salvador da Pátria em 2018" (Drummond et al, 2008). Assim, apontamos que, quando o julgamento se direcionou ao impeachment enquanto vingança, a polarização entre heróis e vilóes residiu naqueles que resistem versus aqueles que se vingam.

Por outro lado, quando o julgamento presente nas matérias culpou Dilma e seus aliados ao longo do processo de impeachment, nota-se a predominância da utilização do espectro de vilão - denotando que a culpa do processo se devia, principalmente, à própria presidenta e seus colegas apoiadores. Para fins de contextualização, a diferença entre vilão e vítima aqui ultrapassa o dobro de matérias. Por fim, tanto as categorias "brigas políticas" quanto "impeachment como forma" apresentaram resultados parecidos: em ambos houve a leve predominância da utilização de vilão em detrimento de vítima. Essa proximidade indica que a cobertura jornalística, paradoxalmente, quando emitiu juízo de valor acerca das brigas políticas, quer dizer, da polarização e do jogo de partidos, reforçou-as ainda mais, apresentando-as num contexto de bem (as vítimas prejudicadas) e mal (os vilóes).

Por fim, o último gráfico diz respeito à verificação das variáveis vítima e vilão à luz da recomendação de tratamento dada pelas matérias analisadas. Aqui, o principal objetivo é verificar como Dilma Rousseff e seus aliados são vistos quando o impeachment é tratado como a melhor solução. 


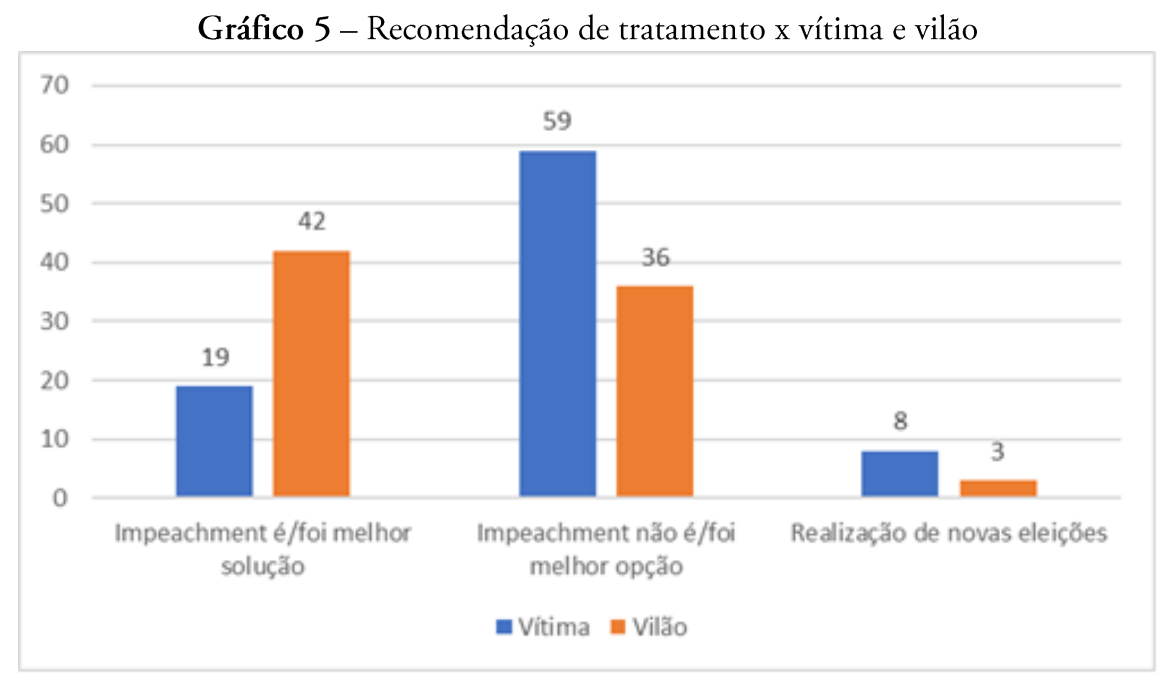

Fonte: Elaboração própria ${ }^{12,13}$.

Cruzando a recomendação de tratamento com as categorias de personalização "vítima" e "vilão", é possível extrair algumas afirmaçôes. A primeira delas vai no sentido de que, quando a ideia de impeachment como melhor solução política apareceu, ela foi tratada majoritariamente sob a perspectiva do viláo, o que provavelmente indica que o governo foi criticado na matéria como causador do próprio impeachment. Tal hipótese pode ser corroborada com os dados apresentados na categoria de tratamento "impeachment não é/foi melhor solução", na qual a lógica permanece a mesma, mas com o polo invertido: aqui a personagem vítima foi a mais utilizada, isso porque - provavelmente - as matérias tratavam o então governo como grupo prejudicado. Por fim, a realização de novas eleições foi a categoria de tratamento menos utilizada, e nela predominou a vítima.

Para uma melhor visualização da interação entre as variáveis, também foram construídas algumas análises de correspondência múltipla ${ }^{14}$ entre narrativa e

12 É possível afirmar que o cruzamento feito é uma associação significativa do ponto de vista estatístico para a variável "sujeito como vítima", com qui-quadrado 114,970 e sig ,000*. A mesma variável também está correlacionada significativamente com a "recomendação de tratamento" (rs=0,375, $\mathrm{p}<0,01)$.

13 Analisando o resíduo padrão desses cruzamentos, é possível perceber uma presença abaixo da esperada na marcação de vítima em relação à recomendação de tratamento "o impeachment é/foi a melhor solução" $(-4,5)$. Por outro lado, existe uma concentração na marcação de vítima quando a recomendação de tratamento é "o impeachment não é/foi a melhor solução" $(5,4)$. 
enquadramento. Essa primeira análise de correspondência foi feita a partir das variáveis de vilão, vítima e herói, que são variáveis de identificação dos personagens, com a variável independente de enquadramento noticioso que contém os atores políticos.

Gráfico 6 - Gráfico de correspondência dos papeis

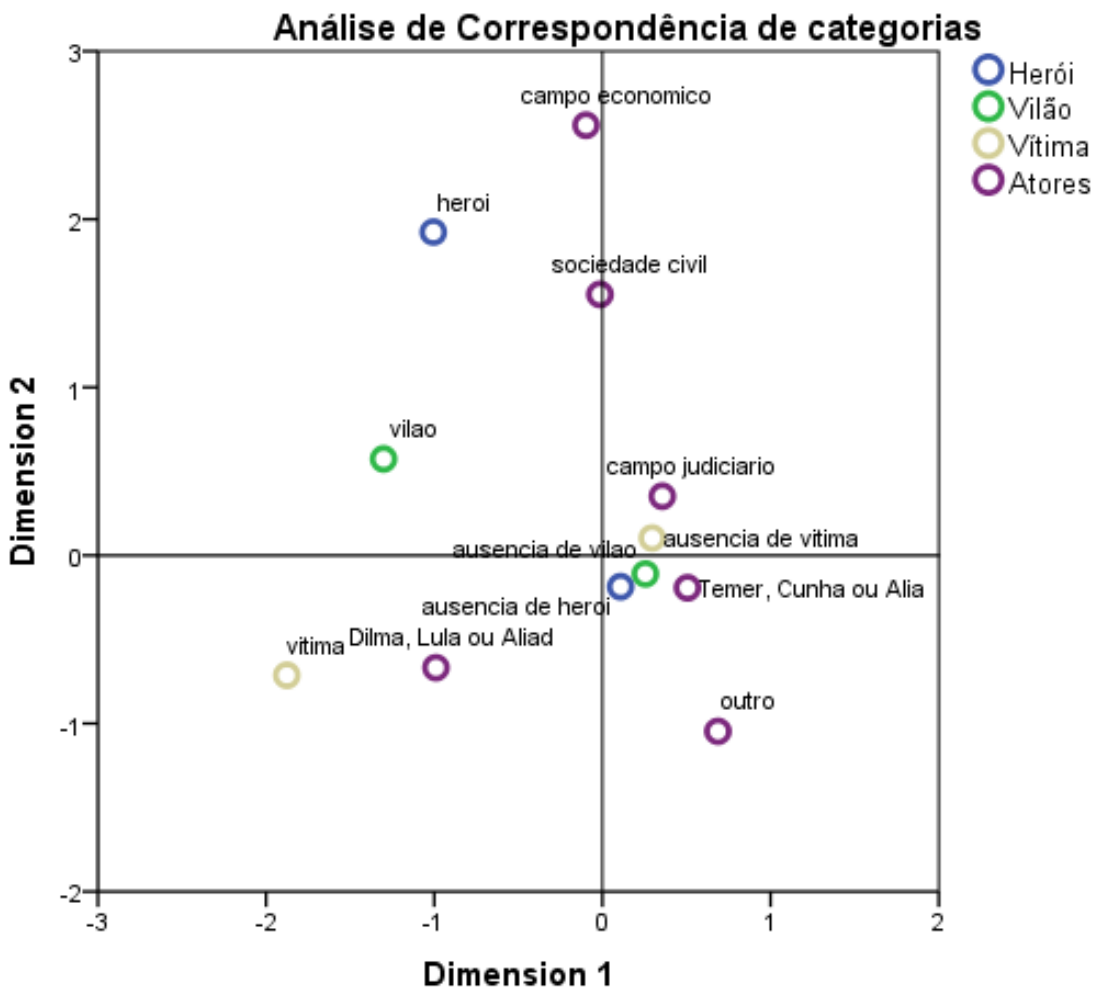

Variable Principal Normalization.

Fonte: Elaboração própria.

Essa análise de correspondência obteve um alfa de cronbach de 0,231, tendo assim uma consistência interna razoável. Quando se observa o gráfico, é possível perceber que os personagens "Dilma, Lula e aliados" estão bem próximos de vítima,

${ }^{14}$ A análise de correspondência múltipla serve para explorar as relaçôes de três ou mais variáveis categóricas, resultando em uma matriz de variáveis indicadoras, na qual cada coluna corresponde a um nível da variável categórica. Desse modo, em vez de avaliar uma tabela com dois fatores da análise de correspondência simples, a tabela com multifatores é recolhida em dimensões para esta análise. 
demonstrando uma construção deste papel, enquanto "Temer, Cunha e aliados" estão mais próximos da ausência de herói e de vilão, demonstrando uma escrita sem construção desses papéis. Por sua vez, fica notável se tratar de uma narrativa em que praticamente nenhum ator político foi tratado como herói, variável que ficou mais próxima ao campo econômico e à sociedade civil.

Gráfico 7 - Gráfico de correspondência narrativa x enquadramento

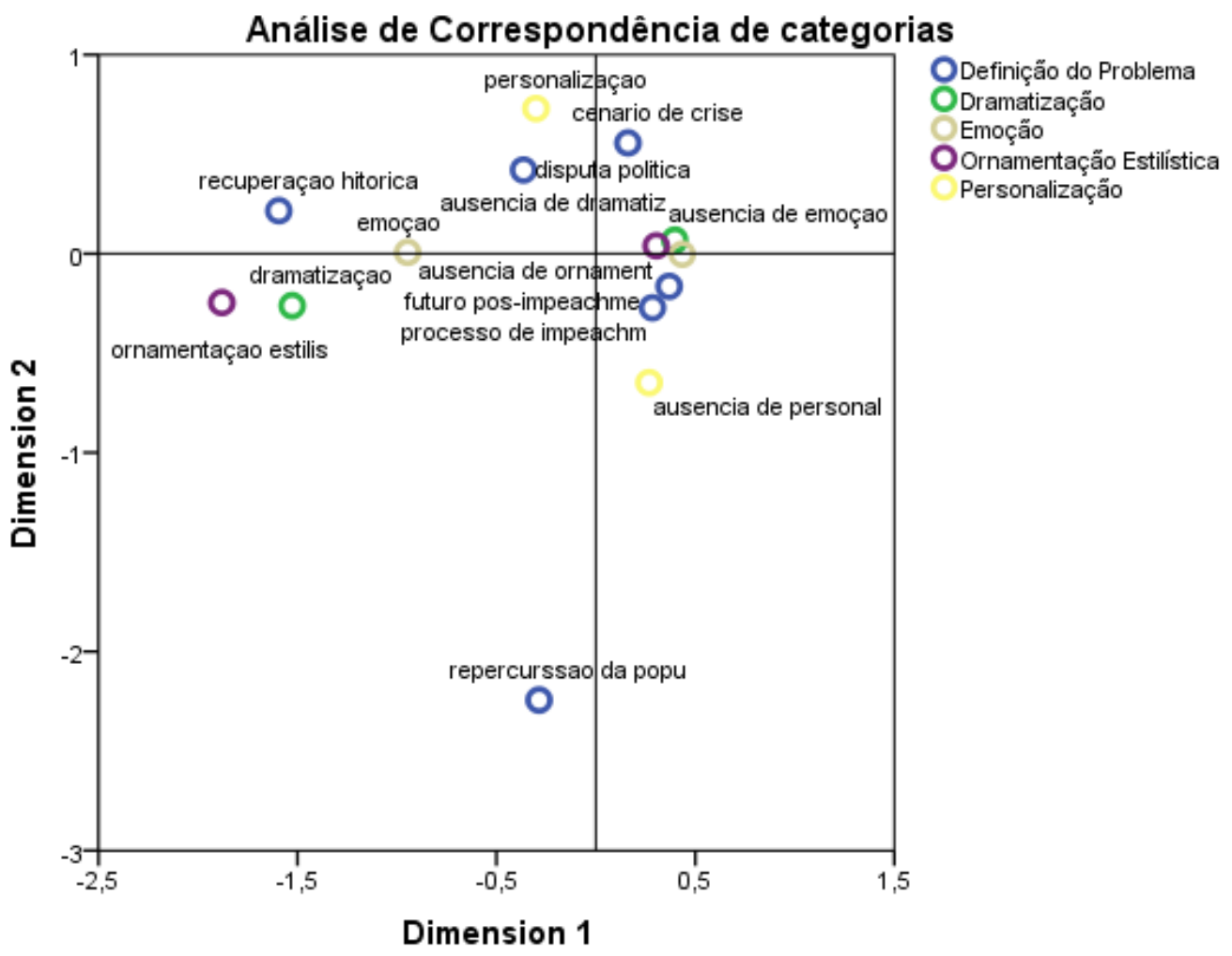

Variable Principal Normalization.

Fonte: Elaboração própria.

Já o Gráfico 7 apresenta um teste de correspondência múltipla cruzando as cinco variáveis de narrativa com a variável de definição do problema do enquadramento, para a qual também se obteve uma alfa de cronbach razoável de 0,399. Nessa análise, é possível perceber um cluster com as ausências narrativas, ausências de dramatização, emoção e ornamentação bem próximas em um quadrante. 
Esse gráfico nos ajuda a visualizar alguns dos achados já demonstrados anteriormente. $\mathrm{Na}$ parte superior, fica mais clara a proximidade entre personalizaçáo, cenário de crise e disputa política, enquanto as matérias jornalísticas sobre o processo de impeachment ou sobre o futuro após o impedimento tendem a não apresentar emoção, ornamentação, dramatização etc. Por sua vez, a repercussão na população também não foi carregada de marcas de narratividade.

\section{Conclusões}

Outro estudo sobre cobertura jornalística do processo de impeachment de Dilma Rousseff analisou as capas do jornal Folha de S. Paulo, usando um corpus de 518 edições do período entre 27 de outubro de 2014, logo após as eleiçóes presidenciais, até 17 de abril de 2016. A análise de enquadramento concluiu que houve "[...] uma baixa diversidade de vozes nas capas e reafirmou-se o discurso de um Brasil em crise" (GUAZINA e SANTOS, 2017).

As autoras perceberam que o tema impeachment já aparece na capa do jornal logo após a reeleição de Dilma Rousseff, na semana seguinte à sua eleição em 2014. Em relação aos temas, o item menos referenciado foi a economia e/ou crise econômica, com quatro ocorrências, representada em 2,3\% dos textos. O baixo índice de popularidade da presidenta totalizou 3,5\% dos textos das capas do jornal. A composição política, mostrando a movimentação dos partidos e políticos e seus posicionamentos, apareceu em $41,5 \%$ dos textos, comprovando a hipótese do golpe como uma articulação da oposição para derrubar um governo indesejado. Do total de capas analisadas, 40 trouxeram o impeachment como manchete principal. As capas buscam apresentar um país em crise e uma chefe do executivo sem condiçóes de governar o país nesse contexto (GUAZINA e SANTOS, 2017).

Ao iniciarmos a pesquisa em tela, partimos da pressuposição já bastante destacada na literatura de que os grandes meios jornalísticos profissionais assumiriam um viés predominantemente negativo contra a presidenta Dilma Rousseff e, consequentemente, favorável ao processo de impeachment. Em uma análise preliminar sobre o enquadramento narrativo (RIZZOTTO, PRUDENCIO e SAMPAIO, 2017) na qual foi analisada uma parte do corpus deste trabalho, composta por 997 notícias, percebeu-se que houve um grau médio de narratividade, sendo o impeachment noticiado muitas vezes como um assunto cotidiano, como algo recorrente da vida política. Verificou-se que mais da metade das matérias apresentavam a personalização, ou seja, o foco em alguns personagens e suas açôes para o relato da reportagem. $\mathrm{Na}$ análise do enquadramento narrativo, ao verificar a 
recorrência dos temas, os autores perceberam que o conflito político-social foi o terceiro tema mais recorrente, abordando as disputas entre o grupo pró e contra o impeachment.

Em outro momento, ao analisar os resultados simplificados, denotamos que o impeachment foi noticiado na maior parte das vezes em termos de assuntos cotidianos, com alta incidência de foco nos personagens políticos e nos conflitos polarizados, definindo, assim, a política em termos de uma luta do bem contra o mal, realizada em espaços institucionalizados e por agentes formais. Ao distanciar a política da rotina dos cidadãos, a cobertura acaba por gerar uma visão negativa dela, que, em certo sentido, incentiva uma despolitização (RIZZOTTO, PRUDENCIO e SAMPAIO, 2017). Posteriormente, buscamos demonstrar que, apesar da cobertura não ser explicitamente favorável ao impeachment, ela tem uma série de pequenas marcações, saliências e destaques que, ao fim, demonstram sim, em nossa visão, um alinhamento de tais meios com a aprovação do impeachment (PRUDENCIO, RIZZOTTO e SAMPAIO, 2018).

Nesta pesquisa, ao cruzar categorias da narrativa com aquelas do enquadramento, nosso objetivo foi justamente evidenciar algumas das formas pelas quais esse alinhamento ou favorecimento ocorreram. Nossa hipótese principal é comprovada na medida em que os valores das variáveis de narratologia eram todos maiores quando havia algum julgamento sobre Dilma e aliados e quando o impeachment foi apresentado como a melhor solução. Em outras palavras, o texto jornalístico tendeu a seguir menos seu protocolo padrão de isenção, abraçando mais emoção, dramatização e personalização quando havia traços positivos de avaliação do impeachment.

Da mesma forma, outro forte indicativo de que os jornais em questão fizeram uma cobertura favorável ao impeachment pode ser visto quando cruzamos os papéis dos personagens com categorias do enquadramento. Como já havíamos destacado anteriormente (PRUDENCIO, RIZZOTTO e SAMPAIO, 2018), Dilma foi frequentemente narrada como vilã ou vítima do processo, enquanto os jogadores políticos favoráveis ao impeachment (Temer, Cunha etc.) foram tratados majoritariamente como vítimas. Denotamos aqui que, quando Dilma e aliados são preponderantes nas matérias, o papel de viláo é o mais visto, assim como quando a ideia de impeachment é considerada a melhor solução política.

Porém, considerando o conteúdo fino das matérias de forma qualitativa, podemos afirmar que Dilma Rousseff foi ora apresentada como vítima do processo 
(apesar de diretamente responsável pela sua derrocada) e ora como vilã, dividindo esse espaço com seu "rival” Eduardo Cunha, também fortemente tratado como um viláo. A diferença entre os dois era o fato de Cunha ser tratado como um viláo que é táo ardiloso que se torna genial, enquanto Dilma sempre esteve à frente de narrativas mais frustradas. Quando o impeachment foi considerado a melhor solução, tanto Dilma quanto Cunha poderiam ser tratados como vilóes, mas novamente a natureza deles tendia a variar na valência. Cunha (e aliados) era aquele que causava dano ao governo, fazia manobras, conhecia regras minúsculas dos procedimentos da Casa, portanto era, de fato, um viláo a ser combatido. Dilma (e aliados), por sua vez, era mais tratada na forma de um governo que causou, ou permitiu que as crises políticas e econômicas acontecessem. E não menos importante, frequentemente Dilma foi vista como vítima do processo de impeachment, sendo gradativamente encurralada e vendo-se sem saída para a crise política e para os desdobramentos do impeachment.

Como denotado por Motta e Guazina (2010), a narrativa do impeachment se centrou basicamente numa história de inúmeros embates, de inúmeros conflitos. Em outras palavras, mesmo fazendo o exercício proposto por Motta (2005) de avaliar a narrativa do fenômeno de maneira longitudinal e heurística, percebemos que o jornalismo noticioso, de fato, não conseguiu escapar das narrativas políticas cotidianas. Enquanto entendemos que a cobertura noticiosa de um acontecimento político da magnitude e complexidade de um impeachment demanda dos jornais estratégias narrativas que objetivam oferecer imagens simbólicas e exemplos com os quais o público possa se identificar, simplificando os meandros da política, esperávamos que jornalistas fossem capazes de compreender e de ressaltar o caráter único do acontecimento em questão. E que, como denota Schudson (2008), para momentos ímpares como esse, fossem capazes de fugir das rotinas jornalísticas e de desenvolver narrativas mais criativas e inovadoras. O que houve na prática foi o uso de mais narratividade dentro do próprio enredo criado pelo jornalismo, que se focou quase que exclusivamente na disputa política entre Dilma e aliados e Cunha e aliados.

Em especial, o que nosso estudo mais evidencia não é necessariamente o viés contra a presidenta Dilma ou seu partido, como ressaltado frequentemente pela literatura de comunicação e política, mas sim a incapacidade reflexiva do jornalismo contemporâneo. Aqui, excetuando-se os espaços de jornalismo opinativo - nos quais, frisamos, o impeachment foi amplamente considerado a melhor solução - foram marginais as matérias que conseguiram abordar de forma mais ampla as questóes complexas envolvidas no impeachment. Por exemplo, o jornalismo brasileiro, em nenhum momento, assumiu a possibilidade de se tratar de um golpe parlamentar, 
sempre tratando a palavra golpe entre aspas. Da mesma maneira, os reflexos ou impactos do impeachment foram, geralmente, ignorados e/ou considerados, no curto prazo, como soluções para a crise política e econômica.

A possibilidade, que depois se mostrou verdadeira, de gerar ainda mais instabilidade política e de gerar um projeto de governo bem diferente daquele eleito pela população não foi considerada. As pautas-bomba, em outro exemplo, foram simplesmente tratadas como estratégias de um lado da disputa política contra o governo Dilma e nunca como pautas-bomba contra a população ou a economia. Pouco houve de um jornalismo mais interpretativo, que buscasse demonstrar os vários interesses políticos e econômicos em jogo, assim como impactos possíveis para a população ou mesmo para a política no longo prazo.

Evidentemente, reconhecemos que o fato de não denotar o impeachment como um evento extraordinário, a escolha por não tratá-lo como um golpe parlamentar, a falta de reflexão sobre impactos em longo prazo, assim como o viés contrário à presidenta Dilma (mesmo que esse não represente a maioria das matérias) podem representar escolhas deliberadas ou mesmo editoriais, o que, em conjunto com um posicionamento mais explícito nos editoriais, pode ser o suficiente para considerar que o jornalismo brasileiro, na melhor das hipóteses, falhou terrivelmente em sua missão de ser o cão de guarda do público. Em relação a outras pesquisas, o que denotamos em nosso trabalho é que isso pode ocorrer de formas menos óbvias ou explícitas que aquelas apontadas anteriormente.

Rafael Cardoso Sampaio é Doutor em Comunicação e Cultura Contemporâneas pela Universidade Federal da Bahia. É Professor Adjunto do Departamento de Ciência Política da Universidade Federal do Paraná e professor do Programa de Pós-Graduação em Ciência Política e do Programa de Pós-Graduação em Comunicação da UFPR. É Co-líder do grupo de pesquisa Comunicação e Participação Política (Compa). E-mail: cardososampaio@gmail.com.

- Carla Rizzotto é Doutora em Comunicação e Linguagens pela Universidade Tuiuti do Paraná. Professora e Pesquisadora do Programa de Pós-Graduação em Comunicação e do Departamento de Comunicação da Universidade Federal do Paraná. Integrante do Grupo de Pesquisa Comunicação e Participação Política (Compa). E-mail: carla_rizzotto@yahoo.com.br. 
Daniela Rocha Drummond é Doutoranda em Ciência Política (UFPR). Bacharel em Comunicação Social - Jornalismo pela PUCPR. Integrante do Grupo de Pesquisa Comunicação e Participação Politica (Compa). E-mail: daniela.imprensacwb@gmail.com.

- Crislaine Franco da Rocha é Mestre em Ciência Política (UFPR). Bacharel em jornalismo pela PUC-PR. Integrante do Grupo de Pesquisa Comunicação e Participação Política (Compa). E-mail: crislainefrancor@gmail.com.

Bruno Nichols Washington é Doutorando em Ciência Politica (UFPR). Mestre em Comunicação (UFPR). Integrante do Grupo de Pesquisa Comunicação e Participação Politica (Compa). E-mail: brunonichols@outlook.com.

- Djiovanni Jonas França Marioto é Mestrando em Ciência Política (UFPR). Bacharel em Ciências Sociais (UFPR). Integrante do Grupo de Pesquisa Comunicação e Participação Política (Compa). Bolsista Capes. E-mail: djiovannimarioto@gmail.com.

\section{Referências}

ALVES, Giovanni et al. Enciclopédia do golpe: o papel da mídia. Bauru: Canal6 Editora, 2018. v. 2. AZEVEDO, Fernando. A Grande Imprensa e o PT: 1989-2014. São Carlos: EDUFSCar, 2017.

BIROLI, Flávia; MANTOVANI, Denise. A parte que me cabe nesse julgamento: a Folha de S. Paulo na cobertura ao processo do "mensalão". Opinião Pública, v. 20, n. 2, p. 204-218, 2014.

CORREIA, João. O admirável mundo das notícias: teorias e métodos. Beira Interior: Labcom, 2011.

DRUMMOND, Daniela et al. A narrativa do impeachment de Dilma Rousseff nas páginas dos jornais brasileiros. Compolítica, v. 8, n. 2, p. 69-100, 11 dez. 2018.

ENTMAN, Robert. Framing: toward a clarification of a fractured paradigm. Journal of Communication, v. 43, n. 4, p. 51-58, 1993.

FERES JÚNIOR, João; SASSARA, Luna. O cão que nem sempre late: o Grupo Globo e a cobertura das eleiçóes presidenciais de 2014 e 1998. Compolítica, v. 6, n. 1, 2016.

GUAZINA, Liziane; PRIOR, Helder; ARAÚJO, Bruno. Enquadramentos de uma crise: o impeachment de Dilma Rousseff em editoriais nacionais e internacionais. In: Encontro da Associação dos Pesquisadores em Comunicação e Política, Porto Alegre, 2017.

GUAZINA, Liziane; SANTOS, Ébida. O impeachment de Dilma Rousseff nas capas da Folha de S. Paulo. In: Encontro Anual da ANPOCS, 41., Caxambu, 2017. 
MARQUES, Francisco.; MONT'ALVERNE, Camila; MITOZO, Isabele. 'Nem Dilma nem Temer': Um estudo quantitativo sobre padrốes de cobertura do impeachment de Dilma Rousseff em editoriais jornalísticos. In: NAPOLITANO, Carlo; VICENTE, Maximiliano, SOARES, Murilo (Org.). Comunicação e Cidadania Política. 1. ed. Bauru: Editoria da UNESP, 2017. v. 1, p. 101126.

MENDONÇA, Ricardo; SIMÓES, Paula. Enquadramento: Diferentes operacionalizaçóes analíticas de um conceito. Revista Brasileira de Ciências Sociais, v. 27, n. 79, p. 187-235, 2012.

MESQUITA, Mário. A personagem jornalística. In: MIRANDA, José; SILVEIR, Joel. As Ciências da Comunicação na Viragem do Século. Comunicação e Linguagens. Lisboa: Veja, 2002.

MOTTA, Luiz. A análise pragmática da narrativa jornalística. In: Congresso Brasileiro de Ciências da Comunicação, 28., Rio de Janeiro, 2005.

MOTTA, Luiz; GUAZINA, Liziane. O conflito como categoria estruturante da narrativa política: o caso do Jornal Nacional. Brazilian Journalism Research, v. 6, n. 1, p. 132-149, 2010.

PÉREZ-LIÑÁN, Aníbal. Presidential impeachment and the new political instability in Latin America. Cambridge: Cambridge University Press, 2007.

PRUDENCIO, Kelly.; RIZZOTTO, Carla; SAMPAIO, Rafael. A normalização do golpe: o esvaziamento da política na cobertura jornalística do "impeachment" de Dilma Rousseff. Revista Contracampo, v. 37, n. 2, p. 8-36, 2018.

RIZZOTTO, Carla.; PRUDENCIO, Kelly; SAMPAIO, Rafael. Tudo normal: a despolitização no enquadramento multimodal da cobertura do impeachment de Dilma Rousseff. Comunicação \& Sociedade, v. 39, p. 111-130, 2017.

SCHUDSON, Michael. Why democracies need an unlovable press. Boston: Polity, 2008.

VIMIEIRO, Ana; MAIA, Rousiley. Enquadramentos da mídia e o processo de aprendizado social: transformações na cultura pública sobre o tema da deficiência de 1960 a 2008. E-Compós, v. 14, p. $1-22,2011$.

WOZNIAK, Antal; LÜCK, Julia; WESSLER, Harmut. Frames, Stories, and Images: The Advantages of a Multimodal Approach in Comparative Media Content Research on Climate Change. Environmental Communication, v. 9, n. 4, p. 469-490, Dec. 2014.

Texto recebido em 24 de abril de 2019. Aprovado em 06 de fevereiro de 2020. 